\title{
Article
}

\section{Oxidation of Refractory Benzothiazoles with PMS/ CuFe2O4: Kinetics and Transformation Intermediates}

\author{
Tao Zhang, Yin Chen, and TorOve Leiknes
}

Environ. Sci. Technol., Just Accepted Manuscript • DOI: 10.1021/acs.est.6b00701 • Publication Date (Web): 04 May 2016

Downloaded from http://pubs.acs.org on May 10, 2016

\section{Just Accepted}

"Just Accepted" manuscripts have been peer-reviewed and accepted for publication. They are posted online prior to technical editing, formatting for publication and author proofing. The American Chemical Society provides "Just Accepted" as a free service to the research community to expedite the dissemination of scientific material as soon as possible after acceptance. "Just Accepted" manuscripts appear in full in PDF format accompanied by an HTML abstract. "Just Accepted" manuscripts have been fully peer reviewed, but should not be considered the official version of record. They are accessible to all readers and citable by the Digital Object Identifier (DOI®). "Just Accepted" is an optional service offered to authors. Therefore, the "Just Accepted" Web site may not include all articles that will be published in the journal. After a manuscript is technically edited and formatted, it will be removed from the "Just Accepted" Web site and published as an ASAP article. Note that technical editing may introduce minor changes to the manuscript text and/or graphics which could affect content, and all legal disclaimers and ethical guidelines that apply to the journal pertain. ACS cannot be held responsible for errors or consequences arising from the use of information contained in these "Just Accepted" manuscripts. 
1

\section{Oxidation of Refractory Benzothiazoles with $\mathrm{PMS} / \mathrm{CuFe}_{2} \mathrm{O}_{4}$ : Kinetics and Transformation Intermediates}

\author{
Submitted by
}

Tao Zhang ${ }^{a}$, Yin Chen ${ }^{b}$, and TorOve Leiknes ${ }^{a^{*}}$ Engineering Division, King Abdullah University of Science and Technology (KAUST), Thuwal 23966-6900, Kingdom of Saudi Arabia

b. School of Chemistry and Chemical Engineering, Central South University, Changsha 410083, People's Republic of China

* Corresponding author: Tel.: + 966-12-8082193.

E-mail address: torove.leiknes@kaust.edu.sa 
TOC Art

17
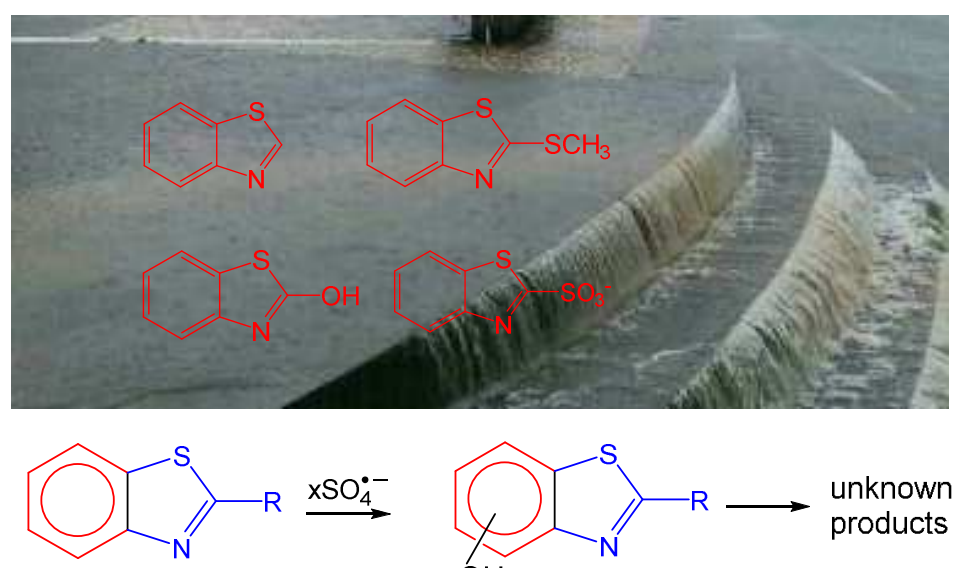

$\mathrm{R}=\mathrm{H}, \mathrm{SO}_{3}{ }^{-}, \mathrm{SCH}_{3}$

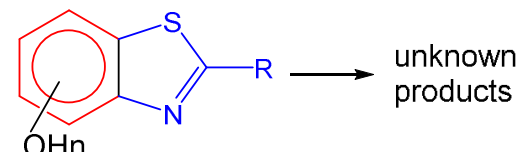

$\bigcirc \mathrm{OH} \stackrel{\mathrm{ysO}_{4}^{--}}{\longrightarrow} \mathrm{N}_{\mathrm{NO}_{2}}^{\mathrm{SO}_{3}^{-}} \longrightarrow \begin{aligned} & \text { unknown } \\ & \text { products }\end{aligned}$ 
18 ABSTRACT

19 Benzothiazole (BTH) and its derivatives, 2-(methylthio)bezothiazole (MTBT),

20 2-benzothiazolsulfonate (BTSA) and 2-hydroxybenzothiazole (OHBT), are refractory pollutants

21 ubiquitously existing in urban runoff at relatively high concentrations. Here, we report their

22 oxidation by $\mathrm{CuFe}_{2} \mathrm{O}_{4}$-activated peroxomonosulfate $\left(\mathrm{PMS} / \mathrm{CuFe}_{2} \mathrm{O}_{4}\right)$, focusing on kinetics and

23 transformation intermediates. These benzothiazoles can be efficiently degraded by this oxidation

24 process which is confirmed to generate mainly sulfate radicals (with negligible hydroxyl-radical

25 formation) under slightly acidic to neutral $\mathrm{pH}$ conditions. The molar exposure ratio of sulfate radical

26 to residual PMS (i.e. $R_{\mathrm{ct}}$ ) of this process is a constant which is related to reaction condition and can

27 be easily determined. Reaction rate constants of these benzothiazoles towards sulfate radical are (3.3

$28 \pm 0.3) \times 10^{9},(1.4 \pm 0.3) \times 10^{9},(1.5 \pm 0.1) \times 10^{9}$ and $(4.7 \pm 0.5) \times 10^{9} \mathrm{M}^{-1} \mathrm{~s}^{-1}$, respectively $(\mathrm{pH} 7$ and

$2920{ }^{\circ} \mathrm{C}$ ). Based on $R_{\mathrm{ct}}$ and these rate constants, their degradation in the presence of organic matter can

30 be well predicted. A number of transformation products were detected and tentatively identified

31 using triple-quadruple/linear ion trap MS/MS and high-resolution MS. It appears that sulfate radicals

32 attack BTH, MTBT and BTSA on their benzo ring via electron transfer, generating multiple

33 hydroxylated intermediates which are reactive towards common oxidants. For OHBT oxidation, it

34 prefers to break down the thiazole ring. Due to competitions of the transformation intermediates, a

35 minimum PMS/pollutant molar ratio of 10-20 is required for effective degradation. The flexible

$36 \mathrm{PMS} / \mathrm{CuFe}_{2} \mathrm{O}_{4}$ could be a useful process to remove the benzothiazoles from low DOC waters like

37 urban runoff or polluted groundwater. 


\section{INTRODUCTION}

40 Benzothiazole derivatives are used in large volumes as vulcanization accelerators and are present

41 in all kinds of rubber-made products. Because of their wide application and various toxicity effects,

42 release of these compounds is of environmental concern. ${ }^{1-3}$ The parent molecules initially applied,

43 such as 2-morpholinothiobenzothiazole, however, are usually not detected in water. It is believed

44 they undergo quick transformations in the environment, ${ }^{4}$ and as such only breakdown products of the

45 parent compounds are frequently detected in urban runoff (e.g. stormwater), treated municipal

46 wastewater and surface waters. Typically four breakdown products are frequently detected, i.e.

47 benzothiazole (BTH), 2-(methylthio)bezothiazole (MTBT), 2-benzothiazolsulfonate (BTSA) and

48 2-hydroxybenzothiazole (OHBT) ${ }^{4-7}$ Concentrations of these compounds are commonly found to

49 be 1 order of magnitude higher in urban runoff (tens of $\mu \mathrm{gL}^{-1}$ ) compared to treated municipal

50 wastewater (several $\left.\mu \mathrm{gL}^{-1}\right){ }^{5}$ This difference is probably due to the dissolution of tiny rubber

51 particles abraded from automobile tires on roads, making urban runoff a major source of these

52 benzothiazoles in aquatic environments. ${ }^{5,8}$ These benzothiazoles are relatively resistant toward

53 abiotic transformation. ${ }^{5}$ They are not effectively removed in current wastewater/stormwater

54 treatment practices. ${ }^{9,}{ }^{10}$ Due to their refractory nature, these compounds have also been found in

55 groundwater and tap water. ${ }^{11}$ Reports show that BTH and OHBT are frequently detected from

56 human urine at levels of $\mathrm{ng} \mathrm{L}^{-1},{ }^{12}$ which possibly is attributed to their existence in drinking water. It

57 is known that BTH, MTBT and OHBT have acute and chronic toxicity effects in the test with

58 Ceriodaphnia dubia, ${ }^{13}$ however, there are still no reports on the possible toxicity of BTSA.

59 The presence of these benzothiazoles in drinking water has raised some healthy concerns. Their

60 removal with oxidation techniques has therefore been investigated, where ozonation, UV irradiation, 
61 and advanced oxidation processes (AOPs) generating hydroxyl radicals (e.g. photocatalytic 62 oxidation, $\mathrm{O}_{3} / \mathrm{H}_{2} \mathrm{O}_{2}$ and $\mathrm{UV} / \mathrm{H}_{2} \mathrm{O}_{2}$ ) have been tested. ${ }^{14-18}$ Results of these studies clearly show that

63 hydroxyl radical is the major oxidant species responsible for effective degradation of benzothiazoles.

64 Unfortunately, their transformation products during hydroxyl radical oxidation are rarely reported,

65 making it difficult to comprehensively assess the effects of their oxidative degradation.

66 In recent years, degradation of refractory pollutants by sulfate radicals has attracted many interests

67 in both research and application. Sulfate radical has a reducing potential comparable to or even

68 higher than hydroxyl radical. ${ }^{19}$ It reacts with compounds normally via electron transfer, and can be

69 more efficient than hydroxyl radical in the degradation of some contaminants. ${ }^{20,21}$ Sulfate radicals

70 can be produced from peroxymonosulfate (PMS) or peroxydisulfate (PDS) during activation with

71 metal ions, ${ }^{22,23}$ metal oxides, ${ }^{24-27}$ alkaline, ${ }^{28}$ heat,${ }^{29} \mathrm{UV}$ irradiation, ${ }^{21,30,31}$ or phenols and quinones. ${ }^{32,}$

$72{ }^{33}$ Magnetically separable $\mathrm{CuFe}_{2} \mathrm{O}_{4}$ was recently developed in our group as well as in several other

73 groups to efficiently activate PMS generating oxidative radicals at neutral $\mathrm{pH}$ while requiring no

74 additional chemicals or energy. ${ }^{34-36}$ The $\mathrm{PMS} / \mathrm{CuFe}_{2} \mathrm{O}_{4}$ is more flexible than hydroxyl radical-based

75 AOPs which usually require ozone and/or UV, and thus could be preferential in the treatment of

76 urban runoff that occurs periodically. Under these conditions, application of ozone and UV is limited

77 by high equipment costs and low operation frequency.

78 We investigated the stability and the surface catalysis mechanism of $\mathrm{CuFe}_{2} \mathrm{O}_{4}$ for PMS activation

79 in our previous work. ${ }^{34}$ However, there is still no idea to determine the concentration distribution of

80 radical species for the application of $\mathrm{PMS} / \mathrm{CuFe}_{2} \mathrm{O}_{4}$ oxidation, especially the transient concentration

81 of sulfate radicals which are of great interest to remove refractory pollutants. Since the sulfate

82 radical concentration cannot be determined, pollutant removal rates in various water matrices 
83 consequently cannot be predicted, which probably impedes practical application of this process as

84 well as other sulfate radical-based oxidation processes. Regarding the highly stable benzothiazoles

85 which are of great concern for the reuse of urban runoff for arid and semi-arid regions, they are

86 rarely studied with sulfate radical oxidation for removal efficiency, kinetics and mechanism. In this

87 work, we established a kinetic method to quantify the transient concentrations of sulfate radical

88 during the $\mathrm{PMS} / \mathrm{CuFe}_{2} \mathrm{O}_{4}$ oxidation, determined reaction rate constants of the four benzothiazoles

89 (BTH, MTBT, BTSA and OHBT) with sulfate radical, tentatively identified their transformation

90 intermediates via LC/high-resolution $\mathrm{MS}$ and $\mathrm{LC} / \mathrm{MS}^{\mathrm{n}}$ analysis, and proposed their degradation

91 pathway accordingly. The results will shed some light on how to determine transient sulfate radical

92 concentrations and predict pollutant removal rates for the $\mathrm{PMS} / \mathrm{CuFe}_{2} \mathrm{O}_{4}$ process as well as for other

93 sulfate radical-based oxidation processes, and also on the effectiveness and mechanism of sulfate

94 radial reactions with highly stable benzo-heterocyclic compounds.

EXPERIMENTAL SECTION

96 Chemicals and materials. Benzothiazole (BTH; 96\%), 2-(methylthio)benzothiazole

97 (MTBT; 97\%), potassium salt of benzothiazolesulfonic acid (BTSA), 2-hydroxybenzothiazole

98 (OHBT; 98\%), N,N-diethyl-m-toluamide (DEET; 97\%), nitrobenzene (NB; $\geq \quad 99 \%)$,

99 2,2'-azino-bis(3-ethylbenzothiazoline-6-sulphonic acid) (ABTS; $\geq 98 \%$ ), peroxomonosulfate (PMS)

100 (Oxone, $\mathrm{KHSO}_{5} \cdot 0.5 \mathrm{KHSO}_{4} \cdot 0.5 \mathrm{~K}_{2} \mathrm{SO}_{4}$ ), and peroxodisulfate (PDS; $\geq 98 \%$ ) were purchased from

101 Sigma-Aldrich. Nitric acid (64 - 66\%), sodium tetraborate $(\geq 99.5 \%)$, and sodium nitrite $(\geq 99 \%)$

102 were purchased from the same company. Methanol (HPLC grade), acetonitrile (HPLC grade), water

103 for LC-MS, formic acid, and ammonium acetate were purchased from Fisher Scientific.

104 6-hydroxybenzothiazole ( $\geq 96 \%)$ and 2-nitrobenzenesulfonic acid $(\geq 97 \%)$ as authentic references of 
105 oxidation products were purchased from TCI America. Information of the benzothiazoles and probe

106 compounds is given in Table 1. The ultrapure water for HPLC elution and experiments was

107 produced with a Milli-Q water system.

108

Table 1. Benzothiazoles and probe compounds used in this study.

\begin{tabular}{|c|c|c|c|c|c|}
\hline Compound & Abbreviation & Structure & $\begin{array}{c}\text { Molecular } \\
\text { weight } \\
\text { (Da) }\end{array}$ & $\log K_{\text {ow }}$ & $\mathrm{p} K_{\mathrm{a}}$ \\
\hline Benzothiazole & BTH & & 135.18 & 2.01 & $1.2^{16}$ \\
\hline 2-Methylthiobenzothiazole & MTBT & & 181.27 & 3.15 & $1.22^{37}$ \\
\hline 2-Hydroxybenzothiazole & OHBT & & 151.18 & 2.12 & $8.9^{16}$ \\
\hline $\begin{array}{l}\text { Benzothiazole-2-sulfonic } \\
\text { acid }\end{array}$ & BTSA & & 214.23 & -0.39 & $2.4-1.0^{7}$ \\
\hline$N, N$-diethyl- $m$-toluamide & DEET & & 191.27 & 2.18 & $0.67^{38}$ \\
\hline Nitrobenzene & - & & 123.11 & 1.85 & - \\
\hline
\end{tabular}

109

110 Hydrophobic acid (HPOA) was extracted from Suwanee river water with XAD-8 resin. efOM was

111 extracted from the effluent of a wastewater treatment plant of Jeddah, Saudi Arabia, also with

112 XAD-8 resin. A street runoff was collected at November $23^{\text {rd }}, 2014$, on KAUST campus (University

113 Boulevard near Harbor Square) during the second precipitation of that month. It was immediately

114 filtered with $0.45 \mu \mathrm{m}$ glass-fiber filters (Whatman), characterized $\left(\mathrm{pH}=7.7, \mathrm{DOC}=3.1 \mathrm{mg} \mathrm{L}^{-1}\right.$, 
$115 \mathrm{UV}_{254}=0.13(1 \mathrm{~cm}$ cell $)$, alkalinity $=22.5 \mathrm{mg} \mathrm{L}^{-1}\left(\mathrm{CaCO}_{3}\right)$, chloride $=13 \mathrm{mg} \mathrm{L}^{-1}$, sulfate $=14 \mathrm{mg}$

$116 \mathrm{~L}^{-1}$, and nitrate $=0.9 \mathrm{mg} \mathrm{L} \mathrm{L}^{-1}$, and stored at $4{ }^{\circ} \mathrm{C}$ before using.

117 The preparation of spinel $\mathrm{CuFe}_{2} \mathrm{O}_{4}$ particles was described in our previous work and showed in

118 detail in Text S1 of Supporting Information (SI). ${ }^{34}$ The spinel oxide particles have characteristic

119 BET surface area of $20.2 \mathrm{~m}^{2} \mathrm{~g}^{-1}$, average pore size of $30 \mathrm{~nm}$, average particle size of $0.3 \mu \mathrm{m}, p \mathrm{H}_{\mathrm{pzc}}$

120 ( $\mathrm{pH}$ at which the surface is zero-charged) of 7.9, and saturated magnetization (M-H) of $24 \mathrm{emu} \mathrm{g}^{-1}$

$121\left(21^{\circ} \mathrm{C}\right)$.

122 Experimental procedure. Kinetic study. Experiments were conducted in a glass bottle

123 wrapped with aluminum foil. Pre-determined volumes of stock solutions of the compound and PMS

124 were injected into $200 \mathrm{~mL}$ Milli-Q water to get desired initial concentrations. Tetra-borate $(10 \mathrm{mM})$

125 rather than phosphate was used as a buffer in most of the reactions, because phosphate is a strong

126 ligand for transition metals. The solution was mechanically stirred during the reaction at a rotary

127 speed of $700 \mathrm{rpm}$ (degradation rates of the bezothiazoles were leveled off at rotation speeds over 550

$128 \mathrm{rpm}$ under the experimental conditions, meaning that the influence of surface diffusion was

129 minimized) and room temperature $\left(20{ }^{\circ} \mathrm{C}\right)$. The reaction was initiated by introducing $\mathrm{CuFe}_{2} \mathrm{O}_{4}$

130 particles into the solution. Samples taken at specific time intervals were filtered with $0.45 \mu \mathrm{m}$

131 glass-fiber syringe filters (Whatman). The filtration was confirmed to have no impact on the

132 concentrations of the target compounds and PMS. For the analysis of the target compounds, sodium

133 nitrite solution was immediately introduced into the filtrate to quench residual PMS. The nitrite was

134 not added to the samples for the analysis of residual PMS. 
135 Oxidation product study. Experiments were conducted in $50 \mathrm{~mL}$ amber glass bottles with Teflon

136 caps. Twenty $\mathrm{mL}$ of the solution containing $0.1 \mathrm{mM}$ of the target compound, various concentrations

137 (0.1-2 mM) of PMS and $1.5 \mathrm{~g} \mathrm{~L}^{-1}$ of $\mathrm{CuFe}_{2} \mathrm{O}_{4}$ particle were introduced into the reaction bottles and 138 shaken at a rotation speed of $300 \mathrm{rpm}$. The PMS concentrations were periodically monitored till 139 complete consumption. Then, the suspensions were filtered through $0.45 \mu \mathrm{m}$ glass-fiber syringe 140 filters (Whatman) for the analysis of target compounds and oxidation products. No reductant was 141 further applied.

142 Analysis. DEET, nitrobenzene, BTH, MTBT, BTSA and OHBT were quantified on a Waters 143 HPLC equipped with a Luna C-18 column $(150 \times 4.6 \mathrm{~mm}, 5 \mu \mathrm{m}$, Phenomenex $)$ at UV wavelengths 144 of 266, 263, 252, 282, 266 and $241 \mathrm{~nm}$, respectively. The column elution condition is shown in 145 Table S1 (SI). The concentration of PMS was analyzed through catalytic transformation of PMS into 146 sulfate radical which reacts instantly with ABTS generating ABTS+. In this method, $0.5 \mathrm{~mL}$ of 147 ATBS solution $(20 \mathrm{mM}), 0.2 \mathrm{~mL}$ of $\mathrm{CoSO}_{4}$ solution $(20 \mathrm{mM})$, and $10 \mathrm{~mL}$ of diluted $\mathrm{H}_{2} \mathrm{SO}_{4}$ solution $148(2 \%)$ were mixed with $1 \mathrm{~mL}$ of the water sample, and then the absorbance at $734 \mathrm{~nm}$ was measured 149 on a spectrometer (DR 500, Hatch). The oxidation of ABTS under this experimental condition was 150 completed within 2 minutes, enabling a kinetic study of PMS decomposition in this work. The 151 calibration curve used for the determination of PMS is shown in Figure S1 (SI).

152 For the kinetic study of benzothiazoles' decomposition in the presence of natural organic 153 matter/effluent organic matter, LC-triple quadrupole/linear ion trap MS/MS (1260 Infinity HPLC, 154 Agilent; Qtrap 5500 mass spectrometer, AB Sciex) operating at multiple reaction monitoring (MRM) 155 mode was applied using the same Luna C-18 column. BTH, MTBT and OHBT were detected at ESI 
156 positive mode; BTSA was detected at ESI negative mode. Column elution conditions and MS

157 settings are shown in Table S2 and Text S2 (SI).

158 Full mass scan and $\mathrm{MS}^{2} / \mathrm{MS}^{3}$ fragmentation scans for the oxidation products (OPs) were

159 conducted with the same LC-Qtrap MS/MS under the same column elution condition. Accurate

160 masses of the OPs were determined on a LC-high resolution MS system (Surveyor HPLC, Thermal;

161 LTQ Orbitrap Velos mass spectrometer, Thermo) with the same column and elution condition. The

162 empirical formulae of these OPs were proposed with Xcalibur software (Thermo). MS settings are

163 shown in Text S2 (SI).

164 Full mass scan with the LC-Qtrap MS was applied to find potential OP peaks. $\mathrm{MS}^{2}$ fragmentation

165 of each potential OPs was conducted to find their characteristic fragments that can be applied for

166 MRM detection. Potential OPs in samples oxidized at PMS/compound molar ratios of 1, 2, 5, 8, 10,

16712,15 and 20 were detected with the LC-Qtrap MS/MS in MRM mode. OP screening was based on

168 1) peak area (obtained with MRM) variation with the PMS/compound molar ratio (the peak area of a

169 reasonable OP should increase or increase and then decrease with PMS dosage), and 2) whether their

170 empirical formulae as determined with LC-Orbitrap MS are reasonable (e.g. numbers of each

171 elements). For OPs confirmed with the above steps, $\mathrm{MS}^{3}$ scan of their major $\mathrm{MS}^{2}$ fragments were

172 conducted with the LC-Qtrap MS/MS to tentatively propose their molecular structures. Because

173 authentic standards are not available to chromatographically confirm most of the proposed structures,

174 Mass Frontier 5.1 software (HighChem), which can predict fragmentation patterns of a given

175 structure based on various known fragmentation mechanisms, was also applied to assist excluding

176 unreasonable isomer structures for the OPs. 
177 OP peaks of BTH and MTBT were much more intensive at ESI positive mode than negative mode.

178 Moreover, no new peaks other than those detected in positive mode were detected at negative mode.

179 So, positive mode ionization was applied in the analysis of OPs of BTH and MTBT. OPs of OHBT

180 and BTSA can only be detected at ESI negative mode.

181 RESULTS AND DISCUSSION

182 Effectiveness of $\mathrm{PMS} / \mathrm{CuFe}_{\mathbf{2}} \mathrm{O}_{\mathbf{4}}$ for benzothiazoles. Figure 1 shows decline of the

183 four benzothiazoles during $\mathrm{PMS} / \mathrm{CuFe}_{2} \mathrm{O}_{4}$ oxidation in pure water. The concentration of these

184 compounds declined quickly under this condition, achieving almost complete removal (i.e. below

185 detection limits of $0.01-0.02 \mu \mathrm{M}$ on the HPLC-UV) within 2 minutes for BTH, OHBT and BTSA at

186 initial PMS/compound molar ratio of 40. For MTBT, its complete removal was also achieved within

1872 minutes when the initial PMS/MTBT molar ratio was raised to 50. Neither PMS alone nor

$188 \mathrm{CuFe}_{2} \mathrm{O}_{4}$ alone can remove the benzothiazoles appreciably (not shown here). This result indicates

189 that the $\mathrm{PMS} / \mathrm{CuFe}_{2} \mathrm{O}_{4}$ oxidation is effective for oxidative degradation of these benzothiazoles. A

190 further eight-cycle $\mathrm{PMS} / \mathrm{CuFe}_{2} \mathrm{O}_{4}$ oxidation was conducted by reclaiming the $\mathrm{CuFe}_{2} \mathrm{O}_{4}$ particles

191 from the reaction solution and reusing them in the next reaction cycle (the experimental and results

192 were shown in Figure S2, SI). The removal of these benzothiazoles in 2 minutes reaction slightly

193 decreased as the $\mathrm{CuFe}_{2} \mathrm{O}_{4}$ was repeatedly reused, but the removal rates in 10 minutes of each

194 reaction cycle were nearly the same, indicating that the activity of the $\mathrm{CuFe}_{2} \mathrm{O}_{4}$ was durable for the

195 oxidation of these benzothiazoles. 


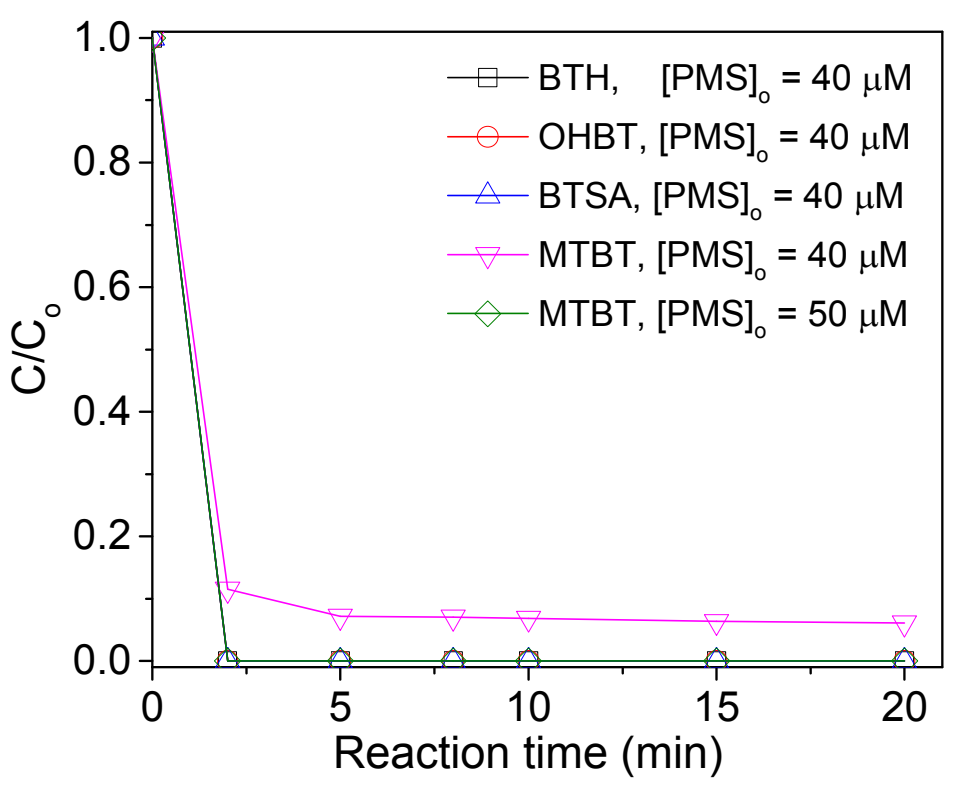

196

197 Figure 1. $\mathrm{PMS} / \mathrm{CuFe}_{2} \mathrm{O}_{4}$ oxidation of individual benzothiazoles. Conditions: dosage of each 198 benzothiazoles $=1 \mu \mathrm{M} ; \mathrm{CuFe}_{2} \mathrm{O}_{4}$ dosage $=200 \mathrm{mg} \mathrm{L}^{-1}$; unbuffered initial $\mathrm{pH}=5.6 ; \mathrm{T}=20^{\circ} \mathrm{C}$.

199 Evaluation of sulfate radical generation within the $\mathrm{PMS} / \mathrm{CuFe}_{\mathbf{2}} \mathbf{O}_{\mathbf{4}}$ process.

200 The $\mathrm{PMS} / \mathrm{CuFe}_{2} \mathrm{O}_{4}$ process produces radicals through surface interactions of the catalyst with PMS

201 (eq 1-4). ${ }^{34}$ The sulfate radical reaction with $\mathrm{OH}^{-}\left(k_{\mathrm{SO}^{-*}, \mathrm{OH}^{-}}=6.5 \times 10^{7} \mathrm{M}^{-1} \mathrm{~s}^{-1}\right)$ also produces

202 hydroxyl radical in water (eq 5), which is more significant at higher $\mathrm{pHs}^{31,39,40}$ Presently, we

203 know that sulfate radical is dominant in this process because pollutant oxidation was scavenged

204 more by ethanol (reactive towards both hydroxyl radical and sulfate radical) than by tert-butanol

205 (more reactive towards hydroxyl radical than towards sulfate radical). ${ }^{34}$ However, exact proportions

206 of these radical species still cannot be quantified. Determination of the concentrations of these

207 radical species is a prerequisite for kinetic studies.

208

$$
\equiv \mathrm{Cu}(\mathrm{II})+\mathrm{HSO}_{5}^{-} \rightarrow \equiv \mathrm{Cu}(\mathrm{II})--(\mathrm{HO}) \mathrm{OSO}_{3}^{-}
$$

$$
\equiv \mathrm{Cu}(\mathrm{II})--(\mathrm{HO}) \mathrm{OSO}_{3}{ }^{-} \rightarrow \equiv \mathrm{Cu}(\mathrm{III})-{ }^{-} \mathrm{OH}+\mathrm{SO}_{4}{ }^{-}
$$




$$
\equiv \mathrm{Cu}(\mathrm{III})-{ }^{-} \mathrm{OH}+\mathrm{HSO}_{5}^{-} \rightarrow \equiv \mathrm{Cu}(\mathrm{II})--^{-} \mathrm{OOSO}_{3}^{-}+\mathrm{H}_{2} \mathrm{O}
$$

$$
2 \equiv \mathrm{Cu}(\mathrm{II})-^{-} \mathrm{OOSO}_{3}^{-} \rightarrow 2 \equiv \mathrm{Cu}(\mathrm{II})+\mathrm{O}_{2}+2 \mathrm{SO}_{4}{ }^{-}
$$

$212 \quad \mathrm{SO}_{4}{ }^{--}+\mathrm{OH}^{-} \rightarrow{ }^{\circ} \mathrm{OH}+\mathrm{SO}_{4}{ }^{2-}$

213 To quantify the radical species (i.e. sulfate radical and hydroxyl radical) generated in the

$214 \mathrm{PMS} / \mathrm{CuFe}_{2} \mathrm{O}_{4}$ process, nitrobenzene $(\mathrm{NB})\left(k_{\mathrm{SO}_{4}^{-}, \mathrm{NB}} \leq 10^{6} \mathrm{M}^{-1} \mathrm{~s}^{-1} ; k_{\mathrm{OH}^{*}, \mathrm{NB}}=3.9 \times 10^{9} \mathrm{M}^{-1} \mathrm{~s}^{-1}\right)^{41,42}$ 215 and $\operatorname{DEET}\left(k_{\mathrm{SO}_{4}{ }^{-}, \mathrm{DEET}}=(1.9 \pm 0.1) \times 10^{9} \mathrm{M}^{-1} \mathrm{~s}^{-1}, \mathrm{pH} 7 ; k_{\mathrm{OH}^{*}, \mathrm{DEET}}=4.95 \times 10^{9} \mathrm{M}^{-1} \mathrm{~s}^{-1}\right)^{38,43}$ were 216 applied as probes in the mixture. Decomposition of PMS, DEET, and NB at pHs between 6.0-8.0 are

217 shown in Figure S3 (SI). The decomposition rates of PMS and DEET were lower at higher $\mathrm{pH}$, 218 because the repulsion between $\mathrm{PMS}$ (mainly in the $\mathrm{HSO}_{5}{ }^{-}$form) and the slightly negatively charged $219 \mathrm{CuFe}_{2} \mathrm{O}_{4}$ surface $\left(p \mathrm{H}_{\mathrm{pzc}}=7.9\right)$ reduces their interaction and the subsequent radical formation. The 220 decline of $\mathrm{NB}$ concentration during $\mathrm{PMS} / \mathrm{CuFe}_{2} \mathrm{O}_{4}$ oxidation was observed to be the same as that of 221 evaporation caused by stirring (i.e. without PMS and $\mathrm{CuFe}_{2} \mathrm{O}_{4}$ in Figure $\mathrm{S} 3 \mathrm{C}$, SI), which means that 222 there was no observable oxidative removal of NB. Based on the reaction rate constants reported in 223 literature shown above, NB reaction with sulfate radicals is extremely slow compared to its reaction 224 with hydroxyl radical and the DEET-sulfate radical reaction. The NB degradation result here 225 indicates clearly that the hydroxyl radical yield is negligible in the $\mathrm{PMS} / \mathrm{CuFe}_{2} \mathrm{O}_{4}$ oxidation, and the 226 DEET is oxidized by sulfate radicals. Therefore, the decomposition of DEET can be described with 227 eq 6 (integrated in eq 7). The $R_{\mathrm{ct}}$, a concept developed by Elovitz and von Gunten to correlate 228 hydroxyl radical generation with ozone decomposition during ozonation, ${ }^{44}$ is adopted here to 229 describe the exposure ratio of sulfate radical to PMS (eq 8). At a given $\mathrm{CuFe}_{2} \mathrm{O}_{4}$ dosage, the 230 decomposition rate of PMS follows a pseudo-first order (Figure S3A, SI), which can be described by 
231 eq 9 , where $k$ is the pseudo first order decomposition rate which can be obtained by plotting the

232 logarithm of normalized PMS residual against reaction time. Then, the exposure of sulfate radical

233 can be expressed as a function of residual PMS during oxidation (eq 10). The DEET residual can

234 thus be described with eq 11.

$235 \quad-\frac{d[\mathrm{DEET}]}{d \mathrm{t}}=k_{\mathrm{SO}_{4}{ }^{-}, \mathrm{DEET}} \cdot\left[\mathrm{SO}_{4}{ }^{-}\right] \cdot[\mathrm{DEET}]$

236

$$
\ln \frac{[\mathrm{DEET}]}{[\mathrm{DEET}]_{0}}=-k_{\mathrm{SO}_{4}{ }^{-\cdot}, \mathrm{DEET}} \cdot \int_{0}^{t}\left[\mathrm{SO}_{4}{ }^{-}\right] d t
$$

$237 \quad R_{\mathrm{ct}}=\frac{\int_{0}^{t}\left[\mathrm{SO}_{4}^{-\cdots}\right] d \mathrm{t}}{\int_{0}^{t}[\mathrm{PMS}] d \mathrm{t}}$

$238 \ln \frac{[\mathrm{PMS}]}{[\mathrm{PMS}]_{\mathrm{o}}}=-k \cdot \mathrm{t}$

$$
\int_{0}^{t}\left[\mathrm{SO}_{4}{ }^{-}\right] d \mathrm{t}=R_{\mathrm{ct}} \cdot \int_{0}^{t}[\mathrm{PMS}] d \mathrm{t}=R_{\mathrm{ct}} \cdot[\mathrm{PMS}]_{0} \cdot \int_{0}^{t} e^{-k \mathrm{t}} d \mathrm{t}
$$

$$
\ln \frac{[\mathrm{DEET}]}{[\mathrm{DEET}]_{0}}=-R_{\mathrm{ct}} \cdot k_{\mathrm{SO}_{4} \cdot, \text { DEET }} \cdot[\mathrm{PMS}]_{0} \cdot \int_{0}^{t} e^{-k \mathrm{t}} d \mathrm{t}
$$

241 Based on the decomposition results of PMS and DEET shown in Figure S3A and S3B (SI), linear 242 relationships were observed between $\ln \frac{[\mathrm{DEET}]}{[\mathrm{DEET}]_{0}}$ and the exposure of residual PMS,

$243[\mathrm{PMS}]_{0} \cdot \int_{0}^{t} e^{-k t} d \mathrm{t}$, at pHs between 6.0-8.0 and also in the presence of the organic matter, HPOA and 244 efOM (Figure 2 with original data in Figure 3S, SI). Results indicates that, under a given condition 245 (i.e. specified water matrix, $\mathrm{PMS}$ and $\mathrm{CuFe}_{2} \mathrm{O}_{4}$ dosages), the $R_{\mathrm{ct}}$ value is a constant. A constant $R_{\mathrm{ct}}$ 246 value under a specific reaction condition indicates that the transient concentration of sulfate radical 
247 is proportional to the residual PMS. This means that sulfate radical cannot be accumulated during the

$248 \mathrm{PMS} / \mathrm{CuFe}_{2} \mathrm{O}_{4}$ oxidation, it should have been rapidly consumed by the organic/inorganic substances

249 and its self-combination reactions just like what happens to hydroxyl radical during ozonation. ${ }^{31,45}$,

$250 \quad{ }^{46}$ As the $R_{\mathrm{ct}}$ value can be easily calculated by monitoring PMS and the probe compound, it provides

251 a simple way to quantify sulfate radical exposure during $\mathrm{PMS} / \mathrm{CuFe}_{2} \mathrm{O}_{4}$ oxidation.

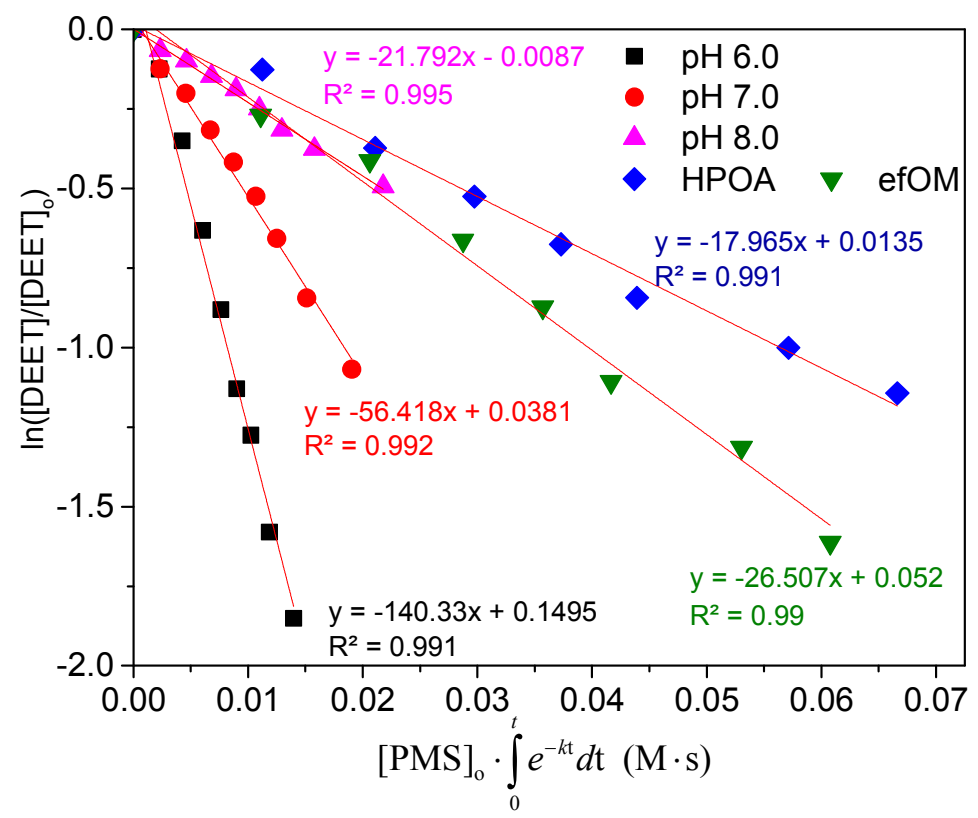

253 Figure 2. Relationship between DEET degradation and the exposure of residual PMS during $254 \mathrm{PMS} / \mathrm{CuFe}_{2} \mathrm{O}_{4}$ oxidation. Conditions in absence of HPOA/efOM: [DEET $]_{\mathrm{o}}=1 \mu \mathrm{M} ;[\mathrm{PMS}]_{\mathrm{o}}=20$ $255 \mu \mathrm{M} ; \mathrm{CuFe}_{2} \mathrm{O}_{4}$ dosage $=200 \mathrm{mg} \mathrm{L}^{-1} ; 10 \mathrm{mM}$ tetraborate buffered; $\mathrm{T}=20^{\circ} \mathrm{C}$. Conditions in presence 256 of HPOA/efOM: HPOA/efOM $=2 \mathrm{mg} \mathrm{DOC} \mathrm{L}{ }^{-1}$; [DEET $]_{\mathrm{o}}=1 \mu \mathrm{M} ;[\mathrm{PMS}]_{\mathrm{o}}=100 \mu \mathrm{M} ; \mathrm{CuFe}_{2} \mathrm{O}_{4}$ 257 dosage $=500 \mathrm{mg} \mathrm{L}^{-1} ; 10 \mathrm{mM}$ tetraborate buffered $\mathrm{pH}=7 ; \mathrm{T}=20^{\circ} \mathrm{C}$. 
263 appreciable adsorption on the $\mathrm{CuFe}_{2} \mathrm{O}_{4}$ (Figure S4, SI), meaning these compounds will be degraded

264 in the solution, and surface adsorption-induced degradation can be excluded.

265 Based on the data shown in Figure S5 (SI), second order rate constants of sulfate radicals with 266 BTH, MTBT, BTSA and OHBT were calculated to be $(3.3 \pm 0.3) \times 10^{9},(1.4 \pm 0.3) \times 10^{9},(1.5 \pm 0.1)$

$267 \times 10^{9}$ and $(4.7 \pm 0.5) \times 10^{9} \mathrm{M}^{-1} \mathrm{~s}^{-1}$, respectively. It was reported that BTH and OHBT react with

268 hydroxyl radicals at rate constants of (3.9-8.6) $\times 10^{9}$ and (4-5.1) $\times 10^{9} \mathrm{M}^{-1} \mathrm{~s}^{-1}$, respectively. ${ }^{16}$ Sulfate

269 radical is thus comparable with hydroxyl radical for BTH and OHBT oxidation. Lutze et al. showed 270 that sulfate radical reacts slower than hydroxyl radical with humic acid and bicarbonate $\left(k_{\mathrm{SO}_{4}{ }^{-}, \mathrm{HA}}=(6.6 \pm 0.4) \times 10^{3} \mathrm{M}^{-1} \mathrm{~s}^{-1} ; k_{\mathrm{OH}^{-}, \mathrm{HA}}=(1.4 \pm 0.2) \times 10^{4} \mathrm{M}^{-1} \mathrm{~s}^{-1} ; k_{\mathrm{SO}_{4}{ }^{-}, \mathrm{HCO}_{3}^{-}}=2.8-9.1 \times 10^{6} \mathrm{M}^{-1} \mathrm{~s}^{-1} ;\right.$

$\left.272 k_{\mathrm{OH}^{\circ}, \mathrm{HCO}_{3}^{-}}=1 \times 10^{7} \mathrm{M}^{-1} \mathrm{~s}^{-1}\right) ;{ }^{40}$ therefore, sulfate radicals could be more effective than hydroxyl radicals 273 for the oxidative removal of BTHs for some real water.

275 Concentrations of residual BTHs during $\mathrm{PMS} / \mathrm{CuFe}_{2} \mathrm{O}_{4}$ oxidation theoretically can be predicted with 276 eq 12 in the presence of organic matter which ubiquitously exist in water. The evolution of the 277 benzothiazoles in the presence of $\mathrm{HPOA} / \mathrm{efOM}$ during $\mathrm{PMS} / \mathrm{CuFe}_{2} \mathrm{O}_{4}$ oxidation is shown in Figure $2783 \mathrm{~A}$ and $3 \mathrm{~B}$. Based on the measured second-order reaction rate constants and the $R_{c t}$ values calculated 279 from eq. 11 with the decomposition data of PMS and DEET (shown in Figure S6 (SI)), the predicted 280 evolution of the concentrations of the benzothiazoles fit well (Figure 3). The degradation of the 281 benzothiazoles spiked into a real street runoff also fitted well with the model prediction (Figure 3C) 282 (PMS and DEET decomposition in the street runoff were shown in Figure S6 (SI)). The result also 283 indicates that a PMS dosage over $200 \mu \mathrm{M}$ is needed for a real street runoff if the less reactive MTBT and BTSA are of concern for their concentration. 
285

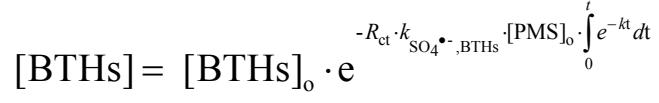

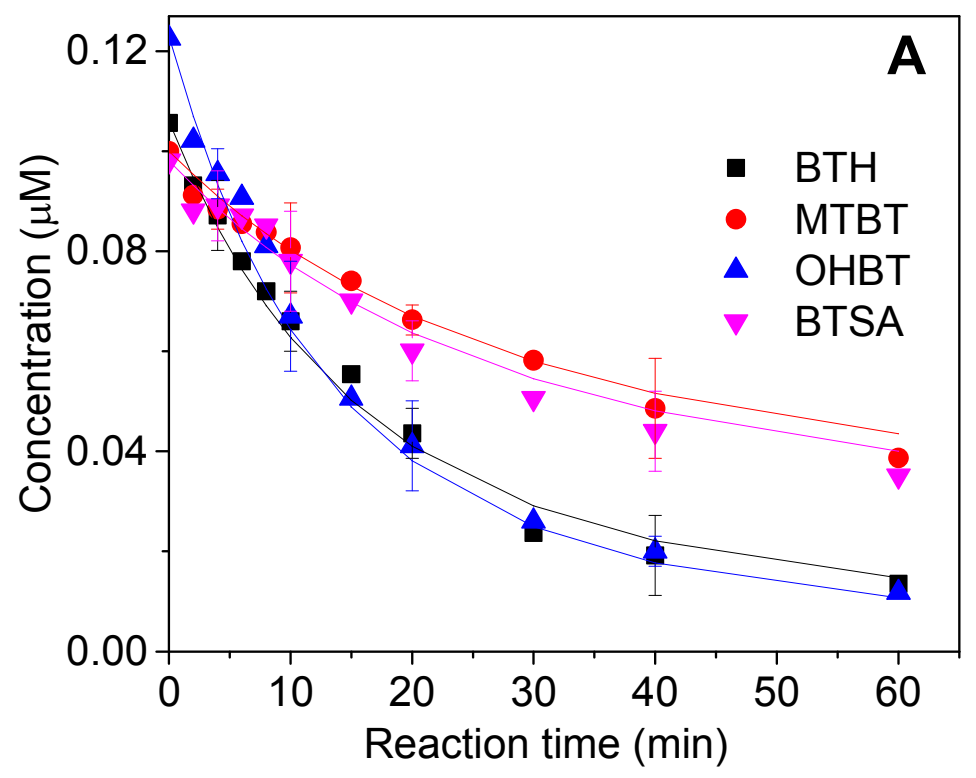

286

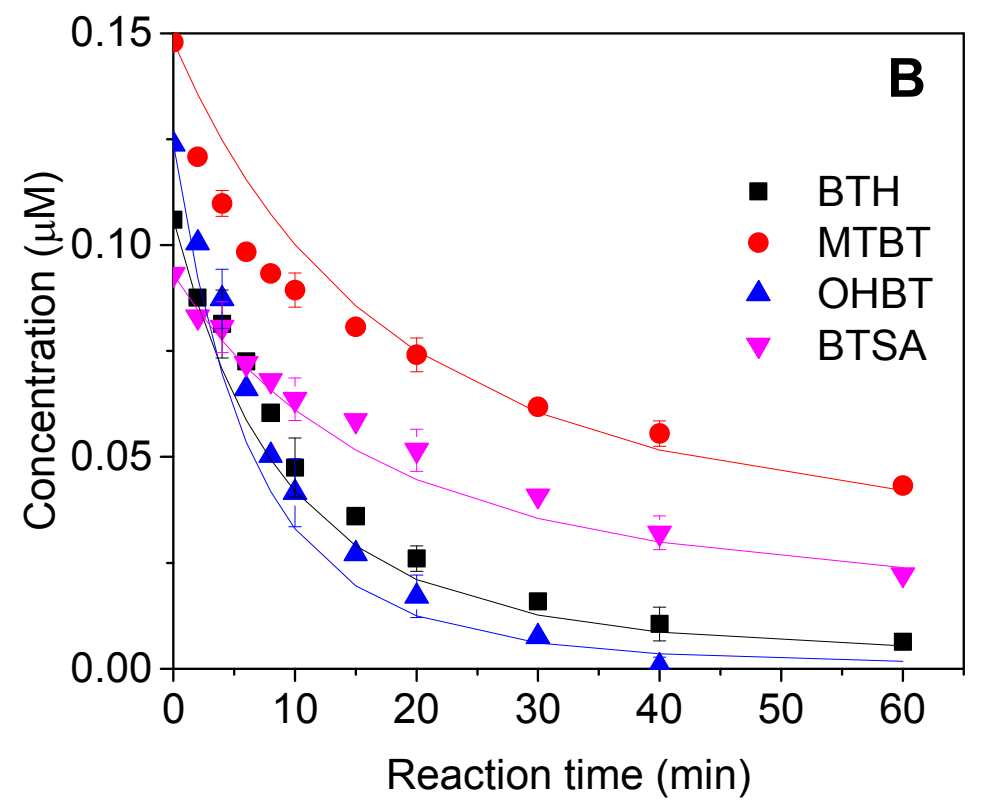




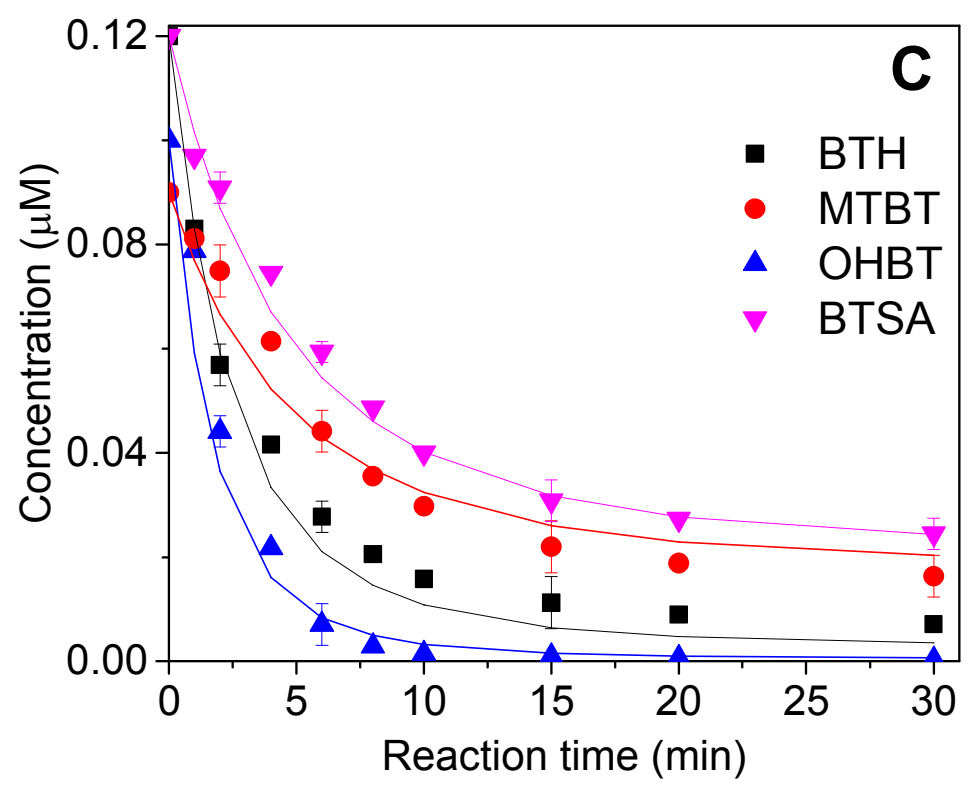

289 Figure 3. Degradation of benzothiazoles in HPOA (A) and efOM (B) solutions and in a street runoff 290 (C): symbols represent measured data, and lines are predicted with the kinetic model. Conditions: 291 PMS dose was $100 \mu \mathrm{M}$ for HPOA and efOM solutions and $200 \mu \mathrm{M}$ for the street runoff; DOC of $292 \mathrm{HPOA} / \mathrm{efOM}$ solutions $=2 \mathrm{mg} \mathrm{L}^{-1} ; \mathrm{CuFe}_{2} \mathrm{O}_{4}$ dosage $=200 \mathrm{mg} \mathrm{L}^{-1}$; HPOA and efOM solutions were 293 buffered to $\mathrm{pH} 7.0$ with $10 \mathrm{mM}$ tetra-borate; $\mathrm{T}=20{ }^{\circ} \mathrm{C}$. Error bars represent standard deviation of 294 three replicates. Transformation products of benzothiazoles formed from $\mathrm{PMS}_{\mathrm{CuFe}} \mathrm{O}_{4}$

297 S3-S6 (SI). Evolution of peak areas of these products (detected with MRM mode) and the 298 benzothiazoles with initial PMS/compound molar ratio are presented in Figure S7-S10 (SI). Since 299 authentic standards for most of these oxidation products are not available, their structures were 300 proposed based on their empirical formulae (Table S3-S6, SI) and $\mathrm{MS}^{2} / \mathrm{MS}^{3}$ fragmentation patterns 301 as summarized in Table S7-S10 (SI). The Mass Frontier 5.1 software was also used to assist in 302 interpreting fragmentation patterns of the parent benzothiazoles and screening possible structures of 303 the oxidation products. 
304 1. Oxidation products of BTH. The fragmentation pattern of BTH provides a basis to interpret the

$305 \mathrm{MS}^{2}$ and $\mathrm{MS}^{3}$ results of the twelve oxidation products. For example, the loss of 27 amu in $\mathrm{MS}^{2}$

306 fragmentation is attributed to the detachment of $\mathrm{CHN}$ from the mother molecule (Table S7, SI).

307 Therefore, a 27 amu loss in the fragmentation of an oxidation product signifies that the $-\mathrm{CH}=\mathrm{N}$ -

308 structure of the thiazole ring is not modified in the oxidation. Consequently, the loss of 44 amu

309 indicates the presence of intact C-S moiety.

310 Four isomers of OP 152 were observed with nearly the same $\mathrm{MS}^{2} / \mathrm{MS}^{3}$ fragmentation pattern

311 (Table S7, SI). According to their accurate masses (Table S3, SI), they have one more O atom than

312 the parent BTH. A loss of water (18 amu) was observed during $\mathrm{MS}^{2}$ fragmentation of OP 152 , which

313 signifies the presence of a hydroxyl group next to an extractable hydrogen. ${ }^{47}$ Since losses of 27

$314(\mathrm{CHN})$ and $44(\mathrm{CS})$ amu were observed respectively in the fragmentation of OP 152 and its

315 fragments, the extra $\mathrm{O}$ atom should not be present on the thiazole ring but on the benzo ring. The

316 retention time of 2-hydroxyl benzothiazole (OHBT) which has one $\mathrm{O}$ atom attached on 2-C of the

317 thiazole ring (16.2 min) didn't match with those of OP 152 under the same column elution

318 conditions (Figure S11, SI). Moreover, there was no direct loss of 27 amu (CHN) from OHBT in

$319 \mathrm{MS}^{2}$ fragmentation (i.e. absence of $\mathrm{m} / \mathrm{z} 125$ (Fig S12, SI)), which also confirms that the

320 hydroxy-benzo structure of OP 152 is reasonable. Only one hydroxylated benzothiazole with $\mathrm{OH}$

321 substitution on the benzo ring was commercially available, i.e. 6-hydroxybenzothiazole. It has the

322 same retention time (13.9 $\mathrm{min})$ and $\mathrm{MS}^{2}$ fragmentation pattern with OP $152-3$, meaning that the

323 structure of this product can be confirmed.

324 OP 168 of BTH has three isomers with two more O atoms than the parent BTH (Table S3, SI).

325 Simultaneous hydroxylation on $\mathrm{C}$ atoms of the thiazole ring and the benzo ring seems impossible, 
326 because sulfate radical-oxidized OHBT sample had no peaks matching the oxidation products of

327 BTH (Figure S11, SI). Losses of $44(\mathrm{CS})$ and $27(\mathrm{CHN})$ amu were observed in further fragmentation

328 of its fragments $\mathrm{m} / \mathrm{z} 150$ (loss of $\mathrm{H}_{2} \mathrm{O}$ ) and 140 (loss of $\mathrm{CO}$ ), respectively (Table S7, SI), indicating

329 that the two $\mathrm{O}$ atoms present on the benzo ring but not on 1-S or 3-N of the thiazole ring. A broken

330 benzo ring having two side aldehyde groups is not a possible structure for OP 168 , because with

331 fragmentation prediction of Mass Frontier 5.1: 1) this structure has no loss of 18 amu $\left(\mathrm{H}_{2} \mathrm{O}\right)$ which

332 was observed for OP 168, and 2) it has a loss of 16 amu (O) due to charge remote rearrangement

333 which was not observed for OP 168 . OP 184 has three isomers with three more $\mathrm{O}$ atoms than the

334 parent BTH. Likewise, the broken benzo ring having olefin alcoholic aldehyde or olefin carboxylic

335 aldehyde groups are not likely structures for OP 184. Purpald test which is sensitive to aldehydes

336 was also applied for the water samples (procedures shown in Text S3, SI), and no aldehyde

337 formation can be noticed. Substitution of three hydroxyl groups on the benzo ring of BTH was thus

338 proposed for OP 184 . OP 182 with two H atoms less than OP184 seems to have a quinone moiety.

339 The loss of $44 \mathrm{amu}(\mathrm{CS})$ during $\mathrm{MS}^{2}$ fragmentation of OP182 as well as the loss of 27 amu (CHN)

340 during $\mathrm{MS}^{3}$ fragmentation of its fragment $\mathrm{m} / \mathrm{z} 110$ indicates that the three $\mathrm{O}$ atoms are present on the

341 benzo ring. The losses of 44 and $27 \mathrm{amu}$ were also observed during $\mathrm{MS}^{3}$ fragmentation of fragments

$342 \mathrm{~m} / \mathrm{z} 182$ and 110 respectively for OP 200 which has four O atoms more than the parent BTH. The

343 substitution of four hydroxyl groups on the benzene ring of BTH was thus proposed as the structure

344 of OP 200. Further oxidation of these hydroxylated products by sulfate radicals likely leads to

345 opening of the aromatic ring forming small carboxylates (as suggested in sulfate radical oxidation of

346 phenol, chlorophenol, and quinone). ${ }^{48,49}$ However, these potential small carboxylate products were 
347 not detected with LC-MS neither in positive nor in negative mode, possibly because they are very

348 hydrophilic and quickly eluted from the column under the analytical condition.

349 Most of the oxidation products like OP 152, OP 168, OP 182 and OP 200 are still quite reactive

350 towards sulfate radicals (Figure S7, SI). It was confirmed in our previous work that radicals can be

351 generated from PMS at a molar ratio of $1: 1$ in the $\mathrm{PMS} / \mathrm{CuFe}_{2} \mathrm{O}_{4}$ process. ${ }^{34}$ Because of competitive

352 consumption of sulfate radicals by these oxidation products, here a PMS/BTH stoichiometry over 12

353 is required to degrade over $90 \%$ of BTH under the experimental conditions. Further experiment was

354 conducted to see whether these oxidation products can be oxidized by cheaper oxidants like

355 peroxodisulfate (PDS) (\$0.74 per kg vs. \$2.2 per kg of PMS) and permanganate (PM) (\$1.5 per kg)

356 which readily react with hydroxylated aromatic structures. ${ }^{32,50}$ PDS and PM were individually

357 introduced into the samples having been oxidized by $\mathrm{PMS} / \mathrm{CuFe}_{2} \mathrm{O}_{4}$ at $\mathrm{PMS} / \mathrm{BTH}=8$ and filtered

358 with $0.45 \mu \mathrm{m}$ filters (i.e. in the absence of $\mathrm{CuFe}_{2} \mathrm{O}_{4}$ particles during PDS or PM oxidation). Dosages

359 of PDS and PM were twice of the initial BTH. In this case, the molar ratio of total oxidant to BTH

360 will be comparable with that of PMS/BTH $=10$. Figure S13 (SI) shows peak areas of the products

361 obtained from PMS/CuFe $\mathrm{O}_{4}$ oxidation at PMS/BTH $=10$ and those further oxidized by PDS and

$362 \mathrm{PM}$ after $\mathrm{PMS} / \mathrm{CuFe}_{2} \mathrm{O}_{4}$ oxidation at $\mathrm{PMS} / \mathrm{BTH}=8$. It is clear that PDS and PM can destroy these

363 oxidation products more effectively than sulfate radicals, which means that most of the products can

364 be selectively oxidized by the common oxidants possibly because of their reactive hydroxy-benzo

365 structures. This result also suggests that a combination of sulfate radicals and common oxidants

366 would be able to improve the efficiency and reduce the cost of oxidation. The combination could

367 also possibly be useful to reduce the formation of toxic products when chloride is present at high 
368 concentrations in the water, as chlorine radicals (formed by sulfate radical oxidation of chloride)

369 readily react with phenolic structures forming chlorinated products. ${ }^{48,49}$

370

371

372

373

374

375

376

377

378

379

380

381

382

383

384

385

386

387

388

389

2. Oxidation products of MTBT. MTBT has losses of $15\left(\mathrm{CH}_{3}\right), 32(\mathrm{~S}), 44(\mathrm{CS}), 27(\mathrm{CHN})$, and 58

(CNS) amu during its $\mathrm{MS}^{2}$ and $\mathrm{MS}^{3}$ fragmentation (Table S8, SI). OP 198, having one more O atom than the parent molecule (Table S4, SI), lost 15, 27, 32, and 44 amu during fragmentation, which means that the thiazole ring and its $-\mathrm{S}-\mathrm{CH}_{3}$ side chain were not modified (i.e. hydroxylation occurred on the benzo ring). The same fragmentation losses were observed for OP 214 which has two isomers and two more $\mathrm{O}$ atoms than MTBT. Two $\mathrm{OH}$-group substitutions on the benzo ring was thus proposed for OP 214. Opening of the benzo ring with formation of two side aldehyde groups was excluded because of the same reason as mentioned for OP 168 of BTH. OP 230 has three isomers and three more $\mathrm{O}$ atoms than MTBT. The losses of 15, 27, 32, and 44 amu were observed during its $\mathrm{MS}^{2}$ and $\mathrm{MS}^{3}$ fragmentations, indicating that the thiazole ring is intact. It should have three $\mathrm{OH}$ groups substituted on the benzo side. Likewise, OP 246 should have four hydroxyl groups substituted on the benzo ring of MTBT, as it has four more $\mathrm{O}$ atoms and losses of 15,32 , 44, and 58 amu during $\mathrm{MS}^{2}$ and $\mathrm{MS}^{3}$ fragmentation. A stoichiometry of PMS/MTBT higher than 20 is required to achieve over $90 \%$ degradation of MTBT (Figure S8, SI). The higher oxidant dose required than BTH oxidation indicates a higher consumption of sulfate radicals by the transformation products of MTBT.

3. Oxidation products of BTSA. BTSA has losses of $64\left(\mathrm{SO}_{2}\right)$ and $28(\mathrm{CO})$ amu during $\mathrm{MS}^{2}$ and $\mathrm{MS}^{3}$ fragmentation respectively at ESI negative mode (Table S9, SI). Successive losses of $80\left(\mathrm{SO}_{3}\right)$ and $76\left(\mathrm{C}_{6} \mathrm{H}_{4}\right)$ amu were also observed. The losses of 64,28 and $80 \mathrm{amu}$ were observed during the fragmentation of OP 230, indicating that the sulfonate group was retained. No loss of 76 amu means 
390 that the benzo ring was modified. The extra O atom of OP 230 compared to BTSA (Table S5, SI)

391 should be present on the benzo ring. Accordingly, di- and tri- hydroxyl substitution on the benzo

392 ring were proposed for OP 246 and OP 262, respectively. OP 260, having two H atoms less than OP

393262 , probably has a hydroxylated quinone ring.

394 4. Oxidation products of OHBT. Losses of $29(\mathrm{CHO}), 43(\mathrm{CHON}), 60(\mathrm{COS})$ and $69\left(\mathrm{C}_{3} \mathrm{H}_{3} \mathrm{ON}\right)$

395 amu were observed for OHBT during negative mode $\mathrm{MS}^{2}$ fragmentation (Table S10, SI). OP 172 ,

396 which is one $\mathrm{C}$ less and two $\mathrm{H}$ and two O more than OHBT (Table S6, SI), has a loss of 64 amu

397 which is characteristic for the sulfonate group as shown in the fragmentation of BTSA (Table S9, SI).

398 A loss of $92 \mathrm{amu}\left(\mathrm{C}_{6} \mathrm{H}_{6} \mathrm{~N}\right)$ was observed, which means that the benzene ring is retained. None of the 399 characteristic fragmentation losses of OHBT was observed for OP 172, indicating a breakage of the 400 structure. Therefore, OP 172 should have a sulfonate group attached on the benzene ring, and the 401 thiazole ring is damaged. OP 202 is two H less and two O more than the OP 172. Since losses of 64, 40280 , and $46\left(\mathrm{NO}_{2}\right)$ amu were observed, the OP 202 should have a sulfonate group and a nitro group 403 attached on the benzene ring, which is reasonable as its retention time and fragmentation pattern 404 matches well with that of 2-nitrobenzenesulfonate. At PMS/OHBT molar ratio of 20, the OHBT 405 dosed $(100 \mu \mathrm{M})$ as well as the OP 172 were nearly completely degraded. In the meantime, the 406 2-nitrobenzenesulfonate produced was determined to be $6.1 \mu \mathrm{M}$, which is much lower than the 407 OHBT dosed, suggesting that this product could be also degradable during the $\mathrm{PMS} / \mathrm{CuFe}_{2} \mathrm{O}_{4}$ 408 oxidation. The degradation of 2-nitrobenzenesulfonate by $\mathrm{PMS} / \mathrm{CuFe}_{2} \mathrm{O}_{4}$ was confirmed as shown in 409 Figure S14 (SI). Its degradation rate was lower than that of OHBT, which could be the reason for its 410 accumulation within the PMS dosages applied here. 
411 Proposed reaction mechanism. According to the structures proposed for the oxidation

412 products, we tentatively conclude that sulfate radicals preferentially attack the benzo ring of BTH,

413 MTBT, and BTSA. For OHBT, sulfate radical attacks more readily the thiazole ring side than the

414 benzo ring.

415 Sulfate radical is a strong electrophile. It attacks organic compounds more preferentially via

416 electron transfer than hydrogen abstraction and addition. ${ }^{19,40}$ Its reaction with benzene via electron

417 transfer is believed to produce hydroxycyclohexadienyl radical through rapid reaction of the benzene

418 radical cation with water. ${ }^{19,51-53}$ It is known that hydroxycyclohexadienyl radical can efficiently

419 react with oxygen forming peroxy radical which further decomposes giving phenol as product. ${ }^{54}$ The

420 study of Anipsitakis et al. shows that sulfate radical reaction with phenol further produces dihydroxy

421 products (catechol and hydroquinone) following the same mechanism. ${ }^{48}$ It seems that the sulfate

422 radical reaction with $\mathrm{BTH}, \mathrm{MTBT}$ and BTSA follows a similar pathway with that of benzene and

423 phenol oxidation (Scheme 1). Once the hydroxylated products are formed, further attack on the

424 electron-enriched benzo ring via electron transfer is more favored, which leads to the formation of

425 products with multiple hydroxyl groups on the benzo ring side of these benzothiazoles. This is also

426 supported by the relatively high stoichiometric ratios of PMS required for effective removal of the

427 parent benzothiazoles. Besides hydroxylated products, quinone-like products were also produced,

428 which possibly proceeds through hydrogen abstraction of the hydroxylated products by either sulfate 429 radical or PMS itself. 
Step 1

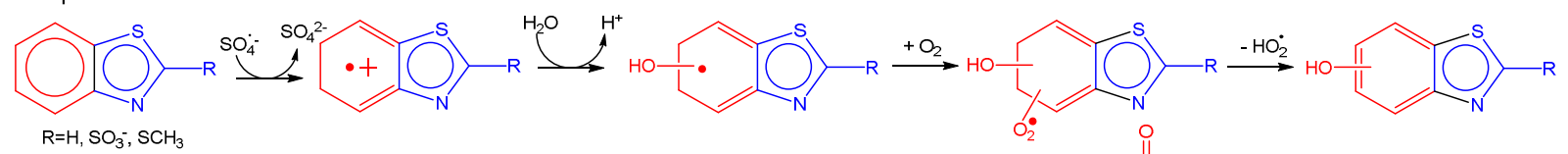

$\mathrm{R}=\mathrm{H}, \mathrm{SO}_{3}^{-}, \mathrm{SCH}_{3}$

Step 2
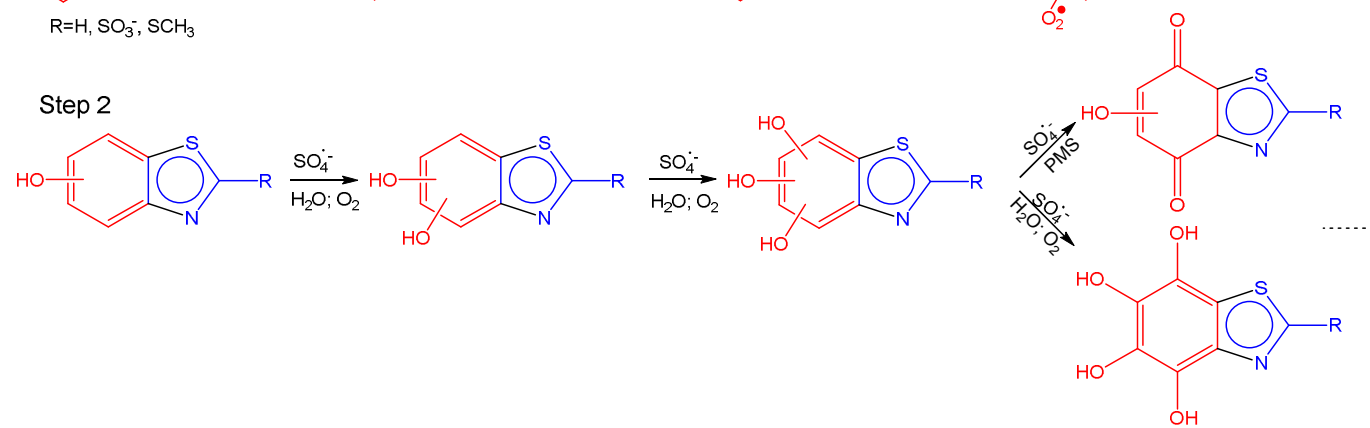

Scheme 1. Proposed degradation pathway of BTH, MTBT and BTSA during PMS/CuFe $\mathrm{O}_{4}$ oxidation.
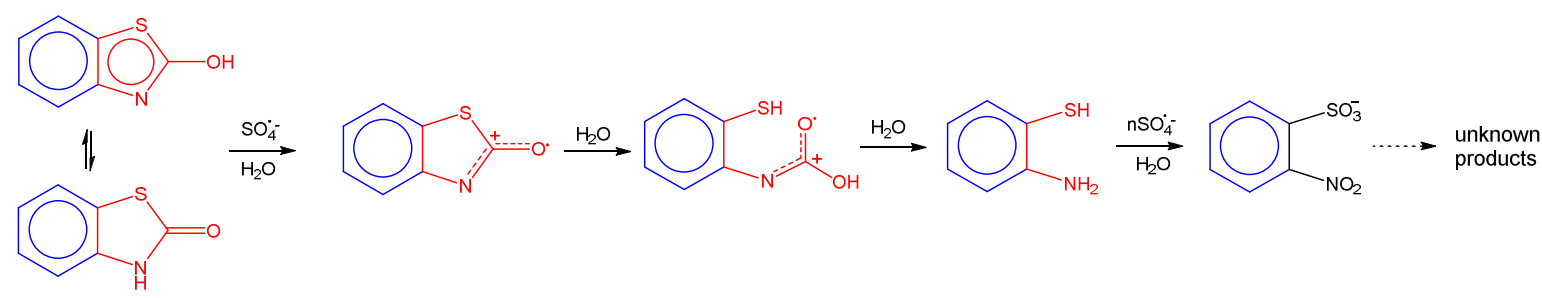

Scheme 2. Proposed degradation pathway of OHBT during $\mathrm{PMS} / \mathrm{CuFe}_{2} \mathrm{O}_{4}$ oxidation.

443 Environmental significance. In arid and semi-arid regions, urban runoff is considered a

444 potential water resource for aquifer recharge or nonpotable reuse after proper treatment. ${ }^{57}$

445 Benzothiazoles usually exist in urban runoff at relatively high concentrations. Effective removal of 
446 them is necessary before aquifer recharge to avoid groundwater pollution. The $\mathrm{PMS} / \mathrm{CuFe}_{2} \mathrm{O}_{4}$ could

447 be a useful oxidation process in this case where the application of other advanced oxidation

448 processes (e.g. $\mathrm{O}_{3} / \mathrm{H}_{2} \mathrm{O}_{2}$ and $\mathrm{UV} / \mathrm{H}_{2} \mathrm{O}_{2}$ ) has more limitations in adaptation to variable precipitation

449 and infrequent operation. Because of its high stability, the $\mathrm{CuFe}_{2} \mathrm{O}_{4}$ can also be fabricated into

450 paving bricks or filtration media for in-situ oxidative treatment of street runoff.

451 This study shows that the removal rates of benzothiazoles during $\mathrm{PMS} / \mathrm{CuFe}_{2} \mathrm{O}_{4}$ oxidation can be

452 predicted with predetermined sulfate radical/PMS exposure ratio. This sulfate radical quantification

453 approach will also be useful in investigating the degradation of other refractory pollutants within this

454 process or other sulfate radical-related oxidation processes. Sulfate radical attack produces multiple

455 hydroxylated intermediates for benzothiazoles (except for OHBT). These hydroxylated products

456 seem readily degradable by cheaper oxidants like peroxydisulfate and permanganate. The

457 combination of sulfate radicals with these common oxidants could be practical and useful to reduce

458 treatment costs and improve the degradation of transformation intermediates.

459 ASSOCIATED CONTENT

460 Supporting Information. Ten tables, fourteen figures and three texts are included in the 461 supporting information. This information is available free of charge via the Internet at 462 http://pubs.acs.org.

463 ACKNOWLEDGEMENTS

464 This research reported in this publication was supported by funding from King Abdullah

465 University of Science and Technology (KAUST). We thank Prof. Jean-Philippe Croué (Curtin 466 University, Australia) for the gift of HOPA and efOM. The assistance of Ms. Tong Zhan and Dr. 
467 Julien Le Roux (WDRC, KAUST) and Mr. Salim Sioud (Analytical Core Lab, KAUST) in MS

468 analysis is gratefully acknowledged. We also appreciate the anonymous reviewers for their revision

469 suggestions which significantly improved the quality of this work.

1. Spies, R. B.; Andresen, B. D.; Rice Jr, D. W., Benzthiazoles in estuarine sediments as indicators of street runoff. Nature 1987, 327, (6124), 697-699.

473 2. Evans, J. J., Rubber tire leachates in the aquatic environment. In Reviews of environmental 474 contamination and toxicology, Springer: 1997; pp 67-115.

475 3. Wik, A.; Dave, G., Occurrence and effects of tire wear particles in the environment-a critical 476 review and an initial risk assessment. Environ. Pollut. 2009, 157, (1), 1-11.

477 4. Reddy, C. M.; Quinn, J. G., Environmental chemistry of benzothiazoles derived from rubber. 478 Environ. Sci. Technol. 1997, 31, (10), 2847-2853.

479 5. Kloepfer, A.; Jekel, M.; Reemtsma, T., Occurrence, sources, and fate of benzothiazoles in 480 municipal wastewater treatment plants. Environ. Sci. Technol. 2005, 39, (10), 3792-3798.

481 6. Grigoriadou, A.; Schwarzbauer, J.; Georgakopoulos, A., Molecular indicators for pollution 482 source identification in marine and terrestrial water of the industrial area of Kavala city, North 483 Greece. Environ. Pollut. 2008, 151, (1), 231-242.

484 7. Wick, A.; Fink, G.; Ternes, T. A., Comparison of electrospray ionization and atmospheric 485 pressure chemical ionization for multi-residue analysis of biocides, UV-filters and benzothiazoles in 486 aqueous matrices and activated sludge by liquid chromatography-tandem mass spectrometry. $J$. 487 Chromatogr. A 2010, 1217, (14), 2088-2103.

488 8. Fries, E.; Gocht, T.; Klasmeier, J., Occurrence and distribution of benzothiazole in the 489 Schwarzbach watershed (Germany). J. Environ. Monit. 2011, 13, (10), 2838-2843.

490 9. Herrero, P.; Borrull, F.; Pocurull, E.; Marcé, R., Efficient tandem solid-phase extraction and 491 liquid chromatography-triple quadrupole mass spectrometry method to determine polar 492 benzotriazole, benzothiazole and benzenesulfonamide contaminants in environmental water samples.

493 J. Chromatogr. A 2013, 1309, 22-32.

494 10. Kloepfer, A.; Jekel, M.; Reemtsma, T., Determination of benzothiazoles from complex aqueous 495 samples by liquid chromatography-mass spectrometry following solid-phase extraction. $J$. 496 Chromatogr. A 2004, 1058, (1), 81-88.

497 11. van Leerdam, J. A.; Hogenboom, A. C.; van der Kooi, M. M.; de Voogt, P., Determination of 498 polar $1 \mathrm{H}$-benzotriazoles and benzothiazoles in water by solid-phase extraction and liquid 499 chromatography LTQ FT Orbitrap mass spectrometry. Int. J. Mass spectrom. 2009, 282, (3), 99-107.

500 12. Asimakopoulos, A. G.; Bletsou, A. A.; Wu, Q.; Thomaidis, N. S.; Kannan, K., Determination of 501 benzotriazoles and benzothiazoles in human urine by liquid chromatography-tandem mass 502 spectrometry. Anal. Chem. 2012, 85, (1), 441-448.

503 13. Nawrocki, S.; Drake, K.; Watson, C.; Foster, G.; Maier, K., Comparative aquatic toxicity 504 evaluation of 2-(thiocyanomethylthio) benzothiazole and selected degradation products using 505 Ceriodaphnia dubia. Arch. Environ. Contam. Toxicol. 2005, 48, (3), 344-350. 
14. Derco, J.; Melicher, M.; Kassai, A.; Dudas, J.; Valicková, M., Removal of Benzothiazoles by ozone pretreatment. Environ. Eng. Sci. 2011, 28, (11), 781-785.

15. Fiehn, O.; Wegener, G.; Jochimsen, J.; Jekel, M., Analysis of the ozonation of 2-mercaptobenzothiazole in water and tannery wastewater using sum parameters, liquid-and gas chromatography and capillary electrophoresis. Water Res. 1998, 32, (4), 1075-1084.

16. Bahnmueller, S.; Loi, C. H.; Linge, K. L.; Von Gunten, U.; Canonica, S., Degradation rates of benzotriazoles and benzothiazoles under UV-C irradiation and the advanced oxidation process $\mathrm{UV} / \mathrm{H}$ 2 O 2. Water Res. 2015, 74, 143-154.

17. Valds, H.; Zaror, C.; Jekel, M., Kinetic study of reactions between ozone and benzothiazole in water. Water Sci. \& Technol. 2004, 48, (11), 505-510.

18. Li, F.; Li, X.; Hou, M., Photocatalytic degradation of 2-mercaptobenzothiazole in aqueous La ${ }^{3+}-\mathrm{TiO}_{2}$ suspension for odor control. Appl. Catal. B: Environ. 2004, 48, (3), 185-194.

19. Neta, P.; Huie, R. E.; Ross, A. B., Rate constants for reactions of inorganic radicals in aqueous solution. J. Phys. Chem. Ref. Data 1988, 17, (3), 1027-1284.

20. Rastogi, A.; Al-Abed, S. R.; Dionysiou, D. D., Sulfate radical-based ferrous-peroxymonosulfate oxidative system for PCBs degradation in aqueous and sediment systems. Appl. Catal. B: Environ. 2009, 85, (3), 171-179.

21. Hori, H.; Yamamoto, A.; Hayakawa, E.; Taniyasu, S.; Yamashita, N.; Kutsuna, S.; Kiatagawa, H.; Arakawa, R., Efficient Decomposition of Environmentally Persistent Perfluorocarboxylic Acids by Use of Persulfate as a Photochemical Oxidant. Environ. Sci. Technol. 2005, 39, (7), 2383-2388.

22. Anipsitakis, G. P.; Dionysiou, D. D., Degradation of Organic Contaminants in Water with Sulfate Radicals Generated by the Conjunction of Peroxymonosulfate with Cobalt. Environ. Sci. Technol. 2003, 37, (20), 4790-4797.

23. Anipsitakis, G. P.; Dionysiou, D. D., Radical Generation by the Interaction of Transition Metals with Common Oxidants. Environ. Sci. Technol. 2004, 38, (13), 3705-3712.

24. Anipsitakis, G. P.; Stathatos, E.; Dionysiou, D. D., Heterogeneous activation of oxone using Co3O4. J. Phys. Chem. B 2005, 109, (27), 13052-13055.

25. Yang, Q. J.; Choi, H.; Chen, Y. J.; Dionysiou, D. D., Heterogeneous activation of peroxymonosulfate by supported cobalt catalysts for the degradation of 2,4-dichlorophenol in water: The effect of support, cobalt precursor, and UV radiation. Appl. Catal. B: Environ. 2008, 77, (3-4), 300-307.

26. Liu, H.; Bruton, T. A.; Doyle, F. M.; Sedlak, D. L., In Situ Chemical Oxidation of Contaminated Groundwater by Persulfate: Decomposition by Fe(III)- and Mn(IV)-Containing Oxides and Aquifer Materials. Environ. Sci. Technol. 2014, 48, (17), 10330-10336.

27. Teel, A. L.; Ahmad, M.; Watts, R. J., Persulfate activation by naturally occurring trace minerals. J. Hazard. Mater. 2011, 196, 153-159.

28. Furman, O. S.; Teel, A. L.; Watts, R. J., Mechanism of Base Activation of Persulfate. Environ. Sci. Technol. 2010, 44, (16), 6423-6428.

29. Johnson, R. L.; Tratnyek, P. G.; Johnson, R. O. B., Persulfate Persistence under Thermal Activation Conditions. Environ. Sci. Technol. 2008, 42, (24), 9350-9356.

30. Lau, T. K.; Chu, W.; Graham, N. J., The aqueous degradation of butylated hydroxyanisole by UV/S2O82-: study of reaction mechanisms via dimerization and mineralization. Environ. Sci. Technol. 2007, 41, (2), 613-619. 
549 31. Guan, Y.-H.; Ma, J.; Li, X.-C.; Fang, J.-Y.; Chen, L.-W., Influence of pH on the Formation of 550 Sulfate and Hydroxyl Radicals in the UV/Peroxymonosulfate System. Environ. Sci. Technol. 2011, $551 \quad 45,(21), 9308-9314$.

552 32. Ahmad, M.; Teel, A. L.; Watts, R. J., Mechanism of persulfate activation by phenols. Environ. 553 Sci. Technol. 2013, 47, (11), 5864-5871.

554 33. Fang, G.; Gao, J.; Dionysiou, D. D.; Liu, C.; Zhou, D., Activation of Persulfate by Quinones: 555 Free Radical Reactions and Implication for the Degradation of PCBs. Environ. Sci. Technol. 2013, 556 47, (9), 4605-4611.

557 34. Zhang, T.; Zhu, H.; Croué, J.-P., Production of Sulfate Radical from Peroxymonosulfate 558 Induced by a Magnetically Separable CuFe2O4 Spinel in Water: Efficiency, Stability, and 559 Mechanism. Environ. Sci. Technol. 2013, 47, (6), 2784-2791.

560 35. Ding, Y.; Zhu, L.; Wang, N.; Tang, H., Sulfate radicals induced degradation of 561 tetrabromobisphenol A with nanoscaled magnetic $\mathrm{CuFe} 2 \mathrm{O} 4$ as a heterogeneous catalyst of 562 peroxymonosulfate. Appl. Catal. B: Environ. 2013, 129, 153-162.

563 36. Guan, Y.-H.; Ma, J.; Ren, Y.-M.; Liu, Y.-L.; Xiao, J.-Y.; Lin, L.-q.; Zhang, C., Efficient 564 degradation of atrazine by magnetic porous copper ferrite catalyzed peroxymonosulfate oxidation 565 via the formation of hydroxyl and sulfate radicals. Water Res. 2013, 47, (14), 5431-5438.

566 37. Pena, M. T.; Vecino-Bello, X.; Casais, M. C.; Mejuto, M. C.; Cela, R., Optimization of a 567 dispersive liquid-liquid microextraction method for the analysis of benzotriazoles and 568 benzothiazoles in water samples. Anal. Bioanal. Chem. 2012, 402, (4), 1679-1695.

569 38. Song, W.; Cooper, W. J.; Peake, B. M.; Mezyk, S. P.; Nickelsen, M. G.; O'Shea, K. E., 570 Free-radical-induced oxidative and reductive degradation of N, $\mathrm{N}^{\prime}$-diethyl-m-toluamide (DEET): 571 Kinetic studies and degradation pathway. Water Res. 2009, 43, (3), 635-642.

572 39. McElroy, W. J., A laser photolysis study of the reaction of sulfate (1-) with chloride and the 573 subsequent decay of chlorine (1-) in aqueous solution. J. Phys. Chem. 1990, 94, (6), 2435-2441. 40. Lutze, H. V.; Bircher, S.; Rapp, I.; Kerlin, N.; Bakkour, R.; Geisler, M.; von Sonntag, C.; Schmidt, T. C., Degradation of Chlorotriazine Pesticides by Sulfate Radicals and the Influence of Organic Matter. Environ. Sci. Technol. 2015, 49, (3), 1673-1680.

41. Neta, P.; Madhavan, V.; Zemel, H.; Fessenden, R. W., Rate constants and mechanism of reaction of sulfate radical anion with aromatic compounds. J. Am. Chem. Soc. 1977, 99, (1), 163-164.

42. Buxton, G. V.; Greenstock, C. L.; Helman, W. P.; Ross, A. B., Critical review of rate constants for reactions of hydrated electrons, hydrogen atoms and hydroxyl radicals $(\cdot \mathrm{OH} / \cdot \mathrm{O}-$ in aqueous solution. J. Phys. Chem. Ref. Data 1988, 17, (2), 513-886. radical-based oxidation: kinetics and mechanism of degradation. Int. J. Environ. Sci. Technol. 2013, 10, (1), 103-112.

44. Elovitz, M. S.; von Gunten, U., Hydroxyl radical/ozone ratios during ozonation processes. I. The Rct concept. Ozone: Sci. \& Eng. 1999, 21, (3), 239-260. 45. Yong, E. L.; Lin, Y.-P., Incorporation of initiation, promotion and inhibition in the R ct concept and its application in determining the initiation and inhibition capacities of natural water in

591 46. Yong, E. L.; Lin, Y.-P., Kinetics of natural organic matter as the initiator, promoter, and 592 inhibitor, and their influences on the removal of ibuprofen in ozonation. Ozone: Sci. \& Eng. 2013, $593 \quad 35,(6), 472-481$. 
594 47. Zimmermann, S. G.; Schmukat, A.; Schulz, M.; Benner, J.; Gunten, U. v.; Ternes, T. A., Kinetic 595 and mechanistic investigations of the oxidation of tramadol by ferrate and ozone. Environ. Sci.

596 Technol. 2011, 46, (2), 876-884.

597 48. Anipsitakis, G. P.; Dionysiou, D. D.; Gonzalez, M. A., Cobalt-Mediated Activation of 598 Peroxymonosulfate and Sulfate Radical Attack on Phenolic Compounds. Implications of Chloride 599 Ions. Environ. Sci. Technol. 2006, 40, (3), 1000-1007.

600 49. Zhang, T.; Chen, Y.; Wang, Y.; Le Roux, J.; Yang, Y.; Croué, J.-P., Efficient Peroxydisulfate 601 Activation Process Not Relying on Sulfate Radical Generation for Water Pollutant Degradation. 602 Environ. Sci. Technol. 2014, 48, (10), 5868-5875.

603 50. Pang, S.-Y.; Jiang, J.; Gao, Y.; Zhou, Y.; Huangfu, X.; Liu, Y.; Ma, J., Oxidation of flame 604 retardant tetrabromobisphenol a by aqueous permanganate: reaction kinetics, brominated products, 605 and pathways. Environ. Sci. Technol. 2013, 48, (1), 615-623.

606 51. Norman, R.; Storey, P.; West, P., Electron spin resonance studies. Part XXV. Reactions of the 607 sulphate radical anion with organic compounds. J. Chem. Soc. B: Phys. Org. 1970, 1087-1095.

608 52. Chawla, O. P.; Fessenden, R. W., Electron spin resonance and pulse radiolysis studies of some 609 reactions of peroxysulfate (SO4. 1, 2). J. Phys. Chem. 1975, 79, (24), 2693-2700.

610 53. Walling, C.; Camaioni, D. M., Aromatic hydroxylation by peroxydisulfate. J. Am. Chem. Soc. 611 1975, 97, (6), 1603-1604.

612 54. Dorfman, L. M.; Taub, I.; Bühler, R., Pulse Radiolysis Studies. I. Transient Spectra and 613 Reaction - Rate Constants in Irradiated Aqueous Solutions of Benzene. J. Phys. Chem. 1962, 36, 614 (11), 3051-3061.

615 55. Kung, K. K.-Y.; Wong, K.-F.; Leung, K.-C.; Wong, M.-K., N-terminal $\alpha$-amino group 616 modification of peptides by an oxime formation-exchange reaction sequence. Chem. Commun. 617 2013, 49, (61), 6888-6890.

618 56. Mahdi Ahmed, M.; Barbati, S.; Doumenq, P.; Chiron, S., Sulfate radical anion oxidation of 619 diclofenac and sulfamethoxazole for water decontamination. Chem. Eng. J. 2012, 197, 440-447.

620 57. Hering, J. G.; Waite, T. D.; Luthy, R. G.; Drewes, J. E.; Sedlak, D. L., A changing framework 621 for urban water systems. Environ. Sci. Technol. 2013, 47, (19), 10721-10726. 